\title{
The Effects of Unemployment Rate Fluctuations on Private Health Insurance Coverage in New Zealand
}

\author{
David Chamberlain and Andrea Kutinova Menclova \\ Department of Economics and Finance \\ University of Canterbury \\ Private Bag 4800 \\ Christchurch, New Zealand
}

\begin{abstract}
In this paper, we estimate the effect of changes in the unemployment rate on private health insurance coverage of New Zealanders using quarterly national data from 1999 to 2009. A one percentage-point increase in the unemployment rate is associated with a decrease of 9,843 lives covered by private health insurance or a 0.32 percentage point decrease in the coverage rate of the total New Zealand population - representing a change of $0.7-1.0 \%$ from the baseline. We also find some evidence of a stronger effect on men and the elderly and of an asymmetric effect on new insurance contracts vs. terminations.
\end{abstract}

JEL Code: I13

Keywords: Private health insurance, Unemployment rate, New Zealand

* We would like to thank the Health Funds Association of New Zealand for providing the data and members of the Economics and Finance Department at the University of Canterbury for helpful feedback. 


\section{Background}

The market for private health insurance is important in New Zealand as it provides the opportunity for individuals to have quicker access to health care than if they were reliant on the public health care system. It can also be an effective way of diverting costs away from the public sector, reducing the strain that health expenditure can have on the government's budget. Currently, approximately a third of New Zealanders have private health insurance coverage. The purpose of this paper is to investigate whether this number can be expected to fluctuate with the business cycle. That is, what effect do changes in the unemployment rate have on the number of individuals covered by private health insurance in New Zealand?

The answer to the above question is important for a number of reasons. The global economy has recently experienced the longest recession since the Great Depression of the 1930s. This has placed government finances under scrutiny, as many governments in developed countries have accumulated large quantities of debt. Healthcare accounts for a large proportion of government expenditure in most countries. In New Zealand, public expenditure on health is the second largest category after Social Security and Welfare. In 2011, public healthcare expenditure accounted for 6.9\% of GDP (New Zealand Treasury 2012). The slow growth and falling tax revenue that accompany a recession can put a strain on the government budget. Private health insurance can be a valuable source of funding to aid the worsened financial position of the public sector. With public expenditure on healthcare expected to double as a percentage of GDP by 2050 (New Zealand Treasury 2009), knowledge about how the unemployment rate impacts private health insurance coverage could be valuable. 


\subsection{New Zealand Healthcare System}

New Zealand has a two-tier healthcare system. All New Zealanders are covered under the public health insurance programme. In addition, they can choose to purchase private health insurance if they desire. The main reason why individuals choose to purchase private health insurance is for the peace of mind of having quick access to elective surgery should they require it. The alternative is to finance the surgery out of their own savings or rely entirely on the public system, which may involve long time delays. Not accounting for self-selection, a 2005 Southern Cross survey (as reported in Styles 2009) found that an individual with private health insurance who had a health condition requiring surgery took on average fourteen days off work, compared to an uninsured individual, who was absent on average forty eight days.

\subsection{Literature Review}

To our knowledge, there are no previous studies examining the effect of unemployment rate fluctuations on private health insurance coverage in New Zealand. Cawley et al. (2011) have conducted research on this topic in the United States. The measures used in their paper differ to this paper for reasons relating to differences in the healthcare systems between the two countries. The main result from their survey is that a one-percentage point increase in the state-level unemployment rate is associated with a 1.67 percentage point $(2.1 \%)$ reduction in the probability that men have health insurance through any source. When applied to the aggregate economy, the results indicate that 9.3 million Americans, mainly working-age men, lost health insurance during the global financial crisis.

These findings are a useful starting point for our purposes but have a limited applicability to the case of New Zealand. The main reason for this are the structural differences between the health care systems of New Zealand and the United States. As mentioned previously, New Zealand has a system of universal health insurance coverage that can be complemented 
with private health insurance if an individual chooses to do so. Most public expenditures on healthcare occur directly through the Ministry of Health via regional District Health Boards. The other significant source of public expenditures on health services in New Zealand is the Accident Compensation Corporation (ACC). ACC is a statutory body under state ownership that provides compulsory no-fault insurance cover for all individuals located in New Zealand. This feature of the New Zealand healthcare system is somewhat unique and augments the public sector's dominant role. In 2010, public expenditure as a share of all healthcare expenditure was $83.2 \%$, ranking New Zealand sixth highest in a survey of OECD countries (OECD Health Data 2012). On the contrary, the United States' healthcare system is dominated by the private sector and there is no universal healthcare coverage. A majority of individuals (59\%) have health insurance provided through their employer. The remaining either purchase health insurance directly $(9 \%)$, obtain coverage through a government programme such as Medicaid (27.8\%), or have no coverage (United States Census Bureau 2010). Only a small percentage of Americans are eligible for Medicaid, though this is set to increase with future changes in legislation. Eligibility is based on income levels and asset holdings. These structural differences between the two countries have implications for the way we classify private health insurance and participation in a public programme in the two countries. Namely, private health insurance and public coverage are replacements for each other in the United States. An individual usually has either one or the other (or neither), with minor overlapping possible in some circumstances. Evidence of this can be seen in the findings from Cawley et al. (2011). As the number of individuals with private health insurance decreased during the financial crisis, the number of individuals covered under public programmes increased. This effect was particularly strong among women and children, who have wider eligibility for public programmes. In contrast, in New Zealand, private health insurance is essentially a supplement to public coverage. From the patient's 
perspective, private health insurance enhances the quality, primarily in terms of fast access to health care, of public coverage. Because of these differences in the role of private health insurance in the two countries, the empirical relationship between the unemployment rate and private health insurance coverage should differ between them. We would expect the demand for private health insurance to be less income elastic in the United States, as individuals should be less willing to terminate their private insurance when their incomes decrease as they do not usually have the public system to fall back on. This means that we would expect the demand for private health insurance to vary relatively more with the business cycle in New Zealand.

However, there is another factor that may cause differing impacts between the two countries: A much higher proportion of private health insurance in the United States is provided through an employer, as opposed to being purchased directly by individuals. This may cause the unemployment rate to have a stronger impact on private health insurance coverage in the United States as people directly lose eligibility for an employment insurance scheme through job loss or a reduction of work hours. This happens in addition to the negative income effect whereas in New Zealand, the negative income effect may be the dominant force affecting private health insurance coverage. Thus, economic theory alone does not give us an unambiguous prediction about the size of our estimated effect relative to that in Cawley et al., (2011) and an empirical analysis is warranted.

\section{Conceptual Framework}

\subsection{Income Effect}

As stated above, the main way we would expect the unemployment rate to impact on private health insurance coverage in New Zealand is through the negative income effect (Table 1). In economic theory, insurance is sometimes classified as an inferior good. The demand for private health insurance may decrease with higher income if individuals exhibit 
decreasing absolute risk aversion. However, health and timely access to medical care can be considered normal goods, and in New Zealand, these objectives can be attained directly through the purchase of private health insurance. Private health insurance coverage in New Zealand is part of discretionary spending and we would expect demand for it to increase with higher income as private health insurance is associated with better health outcomes. This prediction is also supported by Barrett and Conlon (2003) who find that in Australia, the demand for supplemental health insurance increases with income. Therefore, we would expect private health insurance coverage to decrease as the unemployment rate increases. Furthermore, if the unemployment rate increases, health insurance provided through an employer should decrease because of a decrease in the probability that an individual is employed ('employment effect' in Table 1). In addition, during a recession, employment hours are often reduced which may push some employees below the threshold required to be eligible for health insurance through their employer. As discussed previously, effects stemming from changes in group insurance schemes may be relatively smaller in New Zealand than the United States, but with 620,000 New Zealanders covered by group insurance schemes, they will likely be significant. As a higher proportion of men are in the labour force than women, this also means that we would expect the unemployment rate to have a relatively greater impact on the private health insurance coverage of men.

As mentioned by Styles (2009), the negative income effect present during a recession may be particularly strong for the elderly. Many elderly rely on interest payments from their savings as a main source of income. During a recession, interest rates are low, which has an adverse effect on these interest payments and hence the incomes of the elderly. Using data from the Household Economic Survey, Ball and Ryan (2013) confirm that the relative disposable income of fully retired older households as compared to working older households fell substantially during the 2008/09 recession - suggesting that those relying the most on 
interest payments as a source of household income were the most adversely affected. This may result in private health insurance coverage declining by a relatively greater amount for the elderly during a recession. However, the elderly will be less affected by changes in employer-sponsored health insurance, which weakens the above prediction.

\subsection{Financial Constraints}

In addition to the standard income effect (a reduction in the consumption of normal goods), reduced income will lead to people having more difficulty bearing the financial risks associated with a lack of coverage. If individuals lack the savings required to purchase elective surgery should the need arise (and Styles 2009 asserts this is the case for many New Zealanders), they may purchase private health insurance to secure timely access to treatment. This 'certainty effect' (Table 1) would work in the opposite direction to the standard income effect outlined above and may cause expenditure on private health insurance to increase during a recession.

\subsection{Pre-existing Conditions}

Another factor that may influence the effect of the unemployment rate on private health insurance coverage is the treatment of pre-existing conditions in insurance contracts. Preexisting conditions may cause the effective cost of terminating private health insurance coverage to be greater than the actual loss of current coverage (Table 1). In particular, when an individual terminates an insurance contract, it is unlikely that he/she will be able to purchase an identical contract again in the future. Rather, he/she will find it very difficult to reinstate on similar terms as pre-existing health conditions are unlikely to be covered in a future contract. This issue is particularly relevant for the elderly who are significantly more likely to have pre-existing conditions. The legal treatment of pre-existing conditions could 
result in an asymmetric effect on new insurance contracts vs. terminations. We would expect new contracts to be more cyclical than terminations, as individuals should be less willing to terminate contracts due to the possibility that pre-existing conditions will be excluded in future contracts. However, the above theory relies on the ability of the individual to foresee and fully take into account the effect termination today has on the future purchase of an insurance contract. This assumption may be too strong in some cases, especially during a recession when an individual may be focused heavily on current expenditure. If an individual does not take into account the future ramifications of terminating a contract today, terminations may still be strongly cyclical. Styles (2009) expresses concern that the recent recession may have caused people to discontinue their health insurance contracts as a temporary measure, thinking they could easily re-enter when economic conditions improve.

\subsection{Health and the Macroeconomy}

A related issue is whether the 'need' for health care increases in a recession. There is a significant literature addressing the relationship between health and the macroeconomy. The findings to date are mixed. Influential studies by Ruhm and supported by others have found that health is inversely related to the business cycle, with the exception of mental health, which is pro-cyclical (Ruhm 2008, Miller et al. 2009, Gerdthum and Ruhm 2006, Ariizumi and Schirle 2012). The predominant theoretical explanation for this result is that an increase in employment increases the opportunity cost of time. A decrease in employment has the opposite effect, which means that more time may be spent exercising, producing and consuming homemade as opposed to unhealthier mass-produced food, and using preventive medical services. This effect can occur at both the intensive and extensive margins, as the opportunity cost of time may decrease through either a termination of employment or a reduction in labour hours. Evidence from Ruhm (2008) suggests that mortality decreases 
when the economy deteriorates. Specifically, a one percentage-point rise in the unemployment rate is associated with a reduction in the total death rate by $0.5 \%$. Similarly, a one percentage point rise in the unemployment rate is associated with a $1.5 \%$ fall in the prevalence of medical problems and a $1.6 \%$ reduction of 'bed days' measured during the prior two weeks. Other studies have shown that Ruhm's findings cannot be taken as universal for other countries or regions. For example, Svensson (2007) applied Ruhm's empirical methods to the case of Sweden. Like Ruhm, he used acute myocardial infarction (AMI) mortality as a measure of health. AMI mortality is arguably a good measure because it is one of the largest sources of deaths and is influenced by short-term environmental or economic conditions; there is even a significant increase in AMI deaths on Mondays. In contrast to the North American results, Svensson (2007) found a pro-cyclical relationship between economic conditions and health. Similar results have been found in Finland using obesity as a measure of health (Böckerman et al. 2007).

The above literature has implications for our study. If an individual has rational expectations and knowledge of how his/her health may be affected by economic conditions, then this may influence whether he/she purchases or terminates a private health insurance contract ('health effect' in Table 1). An asymmetric effect may again be present if people are hesitant to terminate their coverage during a recession if they think they will increase their utilisation of health care, for example, if they expect their mental health to deteriorate. If Ruhm's findings apply to New Zealand, we would expect increases in the unemployment rate to lower the demand for health care and hence the demand for private health insurance, with the exception of mental health. If the Nordic results apply, demand for private health insurance should increase with increases in the unemployment rate. However, there may also be economic implications of the relationship between health and the business cycle. If the results from North America are applicable to New Zealand, health facilities will be used less 
during a recession which would reduce the strain of health care on the government budget. If the Nordic results apply, then the opposite will be true. A change in the length of queues in the public sector will influence the desire of an individual to purchase private health insurance.

\subsection{Lagged Effect of Unemployment}

It is also important to consider whether the unemployment rate may have a lagged effect on the private health insurance coverage of New Zealanders. It may be that the negative income effect corresponding to an increase in the unemployment rate does not factor into an individual's decision making about purchasing or terminating insurance until later periods. People may view an increase in the unemployment rate as temporary, and wait until the next period to see whether the economy is experiencing a more prolonged slowdown, which may cause them to reconsider their health insurance contracts. Also, the negative income effect associated with a loss of employment or reduced wages may take a while to come into effect. In this case, private health insurance coverage would be influenced by the unemployment rate with a lag effect. There may be other issues regarding timing which are worth considering. If, as predicted, private health insurance decreases with an increase in the unemployment rate, this could increase queues in the public healthcare system as more people become reliant on the public system. These increased queues will then increase the incentive for individuals to purchase private health insurance. The timing of this effect depends on the foresight of the individual. It could be that an individual who currently has private health insurance foresees the increase in queues and this decreases the probability that he/she will terminate a contract in the first place. In this case, the effect will be instantaneous, and could reduce the predicted negative impact of the unemployment rate on private health insurance coverage. Alternatively, individuals may terminate their contracts not taking into account the increase in 
queues that may occur. Once they have terminated their contract, they may experience the increased queues and decide to repurchase an insurance contract. This would cause a positive lag effect of the unemployment rate on insurance contracts, though it would be difficult to measure this empirically and to estimate how long the lag period would be. Finally, it may be that increases in the demand for public health care resulting in longer queues in the public healthcare system have no effect on an individual's decision making. It could be that individuals do not foresee an increase in queues and, if they terminate their coverage, they may still be unaware of any increase in queues if they do not require health care during the period of relatively high unemployment.

Overall, the combined impact of changes in employment and changes in income should be the dominant force affecting the relationship between the unemployment rate and private health insurance coverage. Therefore, we hypothesise that private health insurance coverage will decrease with increases in the unemployment rate ('overall effect' in Table 1).

\section{Empirical Methods}

\subsection{Data}

The data used in estimation has been obtained from the Health Funds Association of New Zealand. It is national, quarterly data and covers the period from January 1999 to September 2009 (so we have 43 time-series observations available). The period covered includes two major recessions: the first occurred in the late 1990s and the second corresponds to the global financial crisis, the effects of which had begun to be heavily felt from mid-2008 until the end of the data period (Figure 1).

\section{[Please insert Figure 1 somewhere here.]}

The small size of the dataset and its time-series nature significantly limit the scope of empirical analyses. Unfortunately, this is the best (only) data available to test our hypotheses 
outlined above. At the time our study was conducted, disaggregated (e.g., regional, District Health Board-level) data on private health insurance coverage did not exist in the public domain. We would much recommend collection of a panel dataset for the purposes of future research. In the meantime, we are pleased to report below some precise estimates obtained even with the limited time-series data.

\subsection{Model}

Our baseline model specification - to be estimated with Ordinary Least Squares - is as follows:

private health insurance coverage $_{q, t}=\alpha+\beta^{*}$ unemployment rate $_{q, t}+\gamma^{*}$ population $_{q, t}+\boldsymbol{\rho}+\boldsymbol{\tau}+\varepsilon_{q, t}$, where $q$ indexes quarters and $t$ indexes years, $\rho$ and $\tau$ are the full sets of quarter and year dummies, respectively, and $\varepsilon$ is a normally distributed error term.

Initially, we use the quarterly number of total lives covered by private health insurance as the dependent variable. The number of New Zealanders with private health insurance has for the most part been increasing over time (Figure 2).

[Please insert Figure 2 somewhere here.]

We set up our baseline model with the unemployment rate (i.e., the number of unemployed persons expressed as a proportion of the labour force) as the main regressor of interest. This is consistent with the literature on this topic as well as the literature examining the effect of the macroeconomy on health status. A variable for total population is included to control for increases in New Zealand population (Figure 3) and ensures that we are measuring the level of coverage, which is what we are interested in, and not the absolute number of contracts.

[Please insert Figure 3 somewhere here.] 
To allow for seasonal patterns in private health insurance coverage, we include quarterly dummy variables in the regression. To control for any trends unassociated with short-term economic conditions, as well as for increases in the real cost of health care that have occurred over time, we include year dummy variables.

It is important to consider whether any variation in the level of public healthcare provided could have an impact on the number of lives covered. That is, are there any supply-side influences affecting the relationship? To indirectly test for this (with the very limited data available), we ran a regression of annual public expenditure on health in New Zealand on the unemployment rate and found no evidence that short-term fluctuations in macroeconomic conditions over the study period had a substantial impact on government expenditure on health. Therefore, the hypothesised effects of the unemployment rate on private health insurance coverage were unlikely to operate via changes to the public health budget. While a methodologically cleaner test of this assertion would be a direct inclusion of public health expenditures in our main model, the annual nature of the government budget data would prevent simultaneous inclusion of year binary variables on the right-hand side.

We also estimate a separate model using coverage rates as the dependent variable. In a sensitivity check (results available on request), we re-estimate our coverage rate models with a double log functional form and our results remain qualitatively the same. Coverage rates are calculated by dividing the number of lives covered by private health insurance in a population or group of interest by the population of the respective group. In our study period, the national coverage rate peaked in early 2000s and then stabilised in 2004 (Figure 4). It is worth noting, however, that these fluctuations were not large. In particular, the maximum reached in the third quarter of 2001 was $34.9 \%$ while the minimum in the second quarter of 2003 was $31.6 \%$. Some of the volatility in the early 2000 s might be attributable to a staged shift of Southern Cross policies between mid-2000 and mid-2002 from 'community-rated' 
ones (with three broad age ranges of 0-18, 19-64, and 65+ years) to 'risk-rated' ones with annual age bands. While the national coverage rate continued to increase during the first part of this staged process and then started decreasing in late 2001, the unemployment rate was gradually decreasing over this entire period. Therefore, there is no reason to believe the shift in Southern Cross rating policies confounds our unemployment estimates. Instead, year binary variables should capture the relatively high coverage rates in years 2000 and 2001.

[Please insert Figure 4 somewhere here.]

We estimate regressions using both dependent variables to account for the various ways in which the unemployment rate may affect private health insurance coverage for different subsets of the population. First, we test for separate gender effects by estimating separate regressions for males and females. These regressions enable us to test the prediction that the insurance coverage of men should be relatively more affected by changes in the unemployment rate (as we would expect due to the higher percentage of men in the workforce). Next, we test for a separate effect on the elderly. Population estimates for the elderly are included to control for 'population ageing' that occurred over the data period. In the conceptual framework, we mentioned that there could be an asymmetric effect of the unemployment rate on new insurance contracts vs. terminations due to the exclusion of preexisting conditions from most new insurance contracts. We test this hypothesis by estimating two separate models: one with new insurance contracts and the other with contract terminations as the dependent variable. We expect the effect of the unemployment rate to be larger in the regression of new insurance contracts.

We also estimate a model using the employment rate, rather than the unemployment rate, as the regressor of interest. This controls for problems that may occur if using the unemployment rate as a sole measure of macroeconomic conditions and is intended as a robustness check. During a recession, there may be individuals who become discouraged and 
drop out of the labour force. These discouraged individuals will no longer be included in the calculation of the unemployment rate. However, the employment rate is calculated as the number of individuals employed as a percentage of the working age population. This means that individuals who drop out of the labour force will still be included in the calculation of the employment rate. The final model that we estimate includes a lag of the unemployment rate. This specification is intended to test whether the effect of the unemployment rate on private health insurance coverage occurs with a delay.

\section{Results}

About a third (33\%) of the New Zealand population has private health insurance coverage and the rate is very similar for men and women (Table 2). Only $25 \%$ of the elderly have private health insurance coverage. Each quarter, about $0.9 \%$ of previously uncovered New Zealanders obtain coverage, on average, and $0.8 \%$ drop existing contracts (Table 2).

[Please insert Table 2 somewhere here.]

The baseline model (Table 3) indicates that a one percentage-point increase in the unemployment rate is associated with a reduction in the total number of lives covered by 9,843 - or $0.7 \%$ from the baseline. This is consistent with our hypothesis that increases in the unemployment rate should decrease the number of lives covered, primarily through the negative income effect and losses of employer-sponsored insurance. This result is marginally significant.

\section{[Please insert Table 3 somewhere here.]}

Regressions using coverage rates as the dependent variable (second column of Table 3) generally yield more statistically significant estimates. For the total New Zealand population, a one percentage-point increase in the unemployment rate corresponds to a significant 0.32 percentage point - or $1.0 \%$ - decrease in the coverage rate. 


\section{[Please insert Table 4 somewhere here.]}

The results from gender-specific regressions (Table 4) are also consistent with our hypothesis that the private health insurance coverage of men is relatively more affected by changes in the unemployment rate. In particular, a one percentage point increase in the unemployment rate is associated with a 0.35 percentage point - or $1.1 \%$ - decrease in the coverage rate for men and a 0.28 percentage point - or $0.9 \%$ - decrease in the coverage rate for women. However, the gender difference does not reach statistical significance in the small dataset available. For the elderly (Table 4), the results indicate that a one percentagepoint increase in the unemployment rate significantly decreases the number of elderly lives covered by 2,750 - or $2.3 \%$ from the baseline. Therefore, there is some evidence that the level of private insurance coverage among the elderly is affected relatively more by changes in the unemployment rate. However, the regression of elderly coverage rates yields a small and statistically insignificant coefficient.

The coefficient on the employment rate (Table 4) has the expected sign but does not reach statistical significance.

The results show evidence of an asymmetric effect of the unemployment rate on new insurance contracts vs. contract terminations (Table 4). In particular, the estimated impact of the unemployment rate on the number of new lives covered is almost three times larger than it is on the number of contracts terminated $(10.5 \%$ vs. $3.6 \%)$. This is an intuitively appealing finding as the largest effect of increases in the unemployment rate should be to deter potential purchases of new insurance contracts. Both coefficients are statistically insignificant but are at least suggestive of individuals being less willing to terminate their contracts with changes in economic conditions due to pre-existing conditions.

There is also evidence in favour of a lagged effect (Table 4). When a lag of the unemployment rate is included in the regression of total lives covered, the size and 
significance of the coefficient on the current unemployment rate variable decrease substantially. In contrast, the coefficient on the lag variable is large and marginally statistically significant. When a second lag is added to the regression (results available on request), the coefficient on the first lag remains large and significant and the coefficient on the second lag is highly insignificant indicating that the unemployment rate affects private health insurance coverage with a one period delay, which in this case corresponds to one quarter. The results from the regressions using coverage rates are also consistent with a one period lag effect occurring.

A possible problem with the use of time series data is autocorrelation in the residuals. In order to determine whether this was an issue we computed the Durbin-Watson statistic. The Durbin-Watson statistic from the baseline regression was 2.63 , which indicates that autocorrelation is not a significant issue affecting the regressions. We also recalculated the regressions of coverage rates using a tobit to ensure that potential clustering of observations at zero and one did not bias our estimates. Reassuringly, the tobit results were qualitatively the same as from Ordinary Least Squares.

\section{Discussion}

Overall, our results indicate that the unemployment rate is systematically associated with private health insurance coverage in New Zealand. The results are largely consistent with our theoretical predictions. Private health insurance coverage for men seems more affected by changes in the unemployment rate than for women. This is likely due to the higher proportion of men in the labour force, which would cause men to be more directly impacted by changes in the unemployment rate. We found some preliminary evidence that the level of insurance coverage of the elderly is relatively more affected by changes in the unemployment rate. This is likely due to the impact economic conditions have on the incomes of the elderly. During 
periods of high unemployment, the loss in income for elderly people driven by low interest rates could be worsening the impact of adverse economic conditions on their insurance coverage relative to the general population. The results also point to an asymmetric effect occurring, as the estimates are consistently larger in the regression of new lives covered relative to contracts terminated. This is intuitively appealing as individuals with private health insurance should be less willing to terminate their coverage with changes in the business cycle as they could face long-term losses in the form of exclusion of pre-existing conditions from future contracts. It appears as though a lag effect is present. This is also intuitively appealing as we would expect individuals to only respond to what they view as prolonged changes in economic conditions, which would require delaying decision-making to see if changes in the unemployment rate are persistent.

It is difficult to numerically compare our results with those in Cawley and Simon (2011) due to the different estimation methods used. In particular, Cawley and Simon used individual-level data, which enabled them to estimate probit regressions to determine the effect changes in the unemployment rate had on the probability of an individual being insured. Our paper made use of national time series data, which means that we are estimating the effect of the unemployment rate on the number of individuals privately insured. Regardless of these differences, there are still observable similarities between the two studies. Namely, both studies find evidence of a significant impact of the unemployment rate on the insurance coverage of men, and in both cases the effect is larger and more significant for men than for women. The effects for older individuals are also larger in both studies.

At the time the study was conducted, the Health Funds Association of New Zealand unfortunately did not stratify their health insurance data by region (or District Health Board). If a panel dataset becomes available in the future, it could provide valuable evidence to add to our initial suggestive findings. 


\section{References}

Ariizumi, H., \& Schirle, T. (2012). Are recessions really good for your health? Evidence from Canada. Social Science and Medicine, 74(8), 1224-1231.

Ball, C., \& Ryan, M. (2013). New Zealand households and the 2008/09 recession. New Zealand Treasury Working Paper 13/05.

Barrett, G.F, \& Conlon, R. (2003). Adverse selection and the decline in private health insurance coverage in Australia: 1989-95. Economic Record, 79(246), 279-296.

Böckerman, P., Johansson, E., Helakorpi, S., Prättälä, R., Vartiainen, E., \& Uutela, A. (2007). Does a slump really make you thinner? Finnish micro-level evidence 1978-2002. Health Economics, 16(1), 103-107.

Cawley, J., \& Simon, K.I. (2005). Health insurance coverage and the macroeconomy. Journal of Health Economics, 24(2), 299-315.

Cawley, J., Moriya, A.S., \& Simon, K.I. (2011). The impact of the macroeconomy on health insurance coverage: Evidence from the great recession. NBER Working Paper No. 17600.

Gerdtham, U.G., \& Ruhm, C.J. (2006). Deaths rise in good economic times: Evidence from the OECD. Economics and Human Biology, 4(3), 298-316.

New Zealand Ministry of Health. (2010). Health expenditure trends in New Zealand 19982008. Wellington: New Zealand Ministry of Health. 
New Zealand Treasury. (2009) NZ health system: The future is now. Retrieved from http://www.treasury.govt.nz/publications/informationreleases/health/longterm/pdfs/mlthepres-system-12may09.pdf

New Zealand Treasury. (2012) Financial statements of the government of New Zealand. Retrieved from http://www.treasury.govt.nz/downloads/pdfs/fsgnz-year-jun12-1.pdf

OECD. (2012) OECD health data. Retrieved from

http://www.oecd.org/els/healthpoliciesanddata/oecdhealthdata2012-

frequentlyrequesteddata.htm

Ruhm, C.J. (2000). Are recessions good for your health? Quarterly Journal of Economics, $115(2), 617-650$.

Ruhm, C.J. (2005). Healthy living in hard times. Journal of Health Economics, 24(2), 341363.

Ruhm, C.J. (2007). A healthy economy can break your heart. Demography, 44(4), 829-848.

Statistics New Zealand (2010). A guide to unemployment statistics. Wellington: Statistics New Zealand.

Styles, R. (2009). Health insurance more important than ever in a recession. Cover Stories: Health Insurance News, 3(1), 1-3. 
Svensson, M. (2007). Do not go breaking your heart: Do economic upturns really increase heart attack mortality? Social Science and Medicine, 65(4), 833-841.

Svensson, M., \& Krüger, N.A. (2012). Mortality and economic fluctuations: Evidence from wavelet analysis for Sweden 1800-2000: Evidence from wavelet analysis for Sweden 18002000. Journal of Population Economics, 25(4), 1215-1235.

United States Census Bureau. (2010). Health status, health insurance, and medical services utilization. Retrieved from http://www.census.gov/prod/2012pubs/p70-133.pdf 
Figure 1.

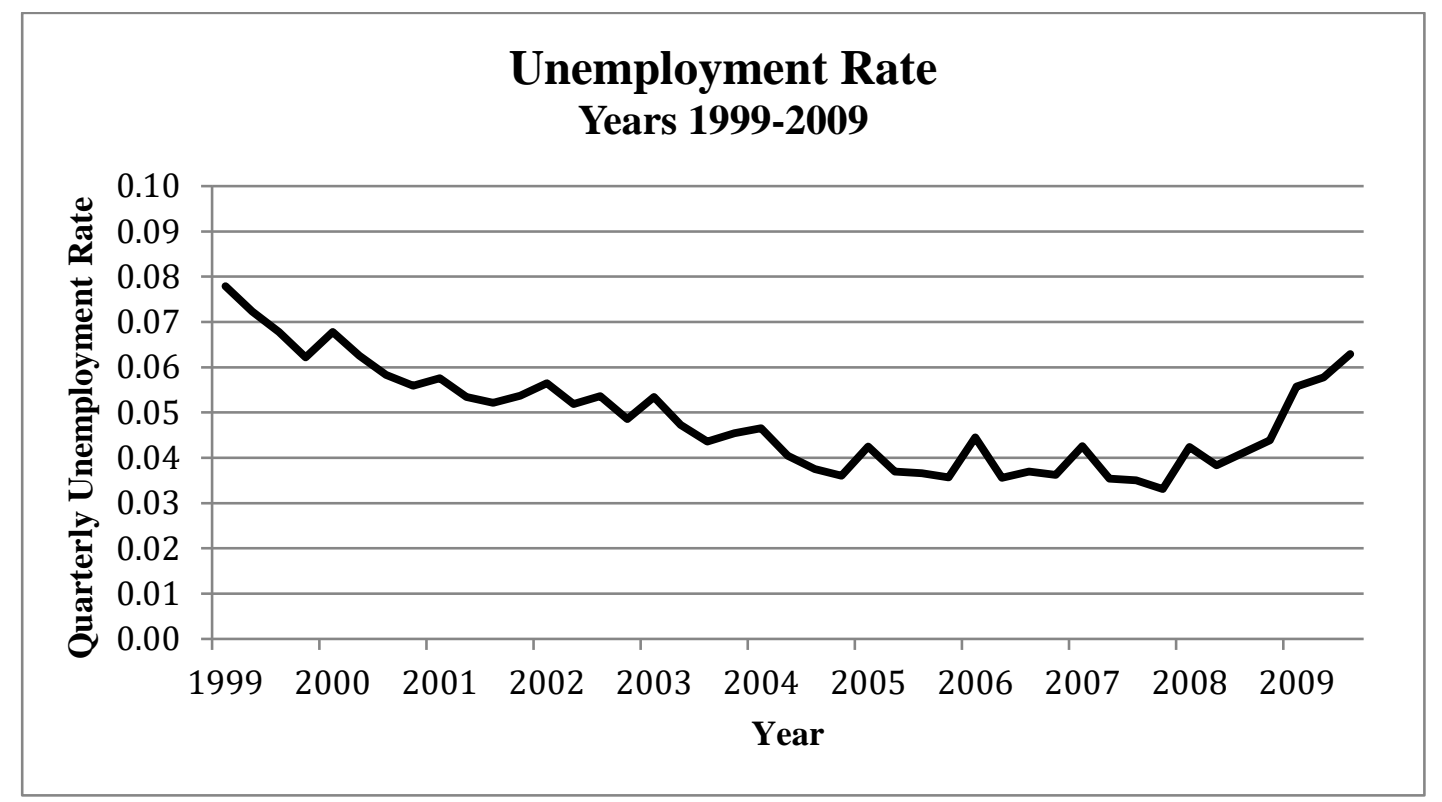


Figure 2.

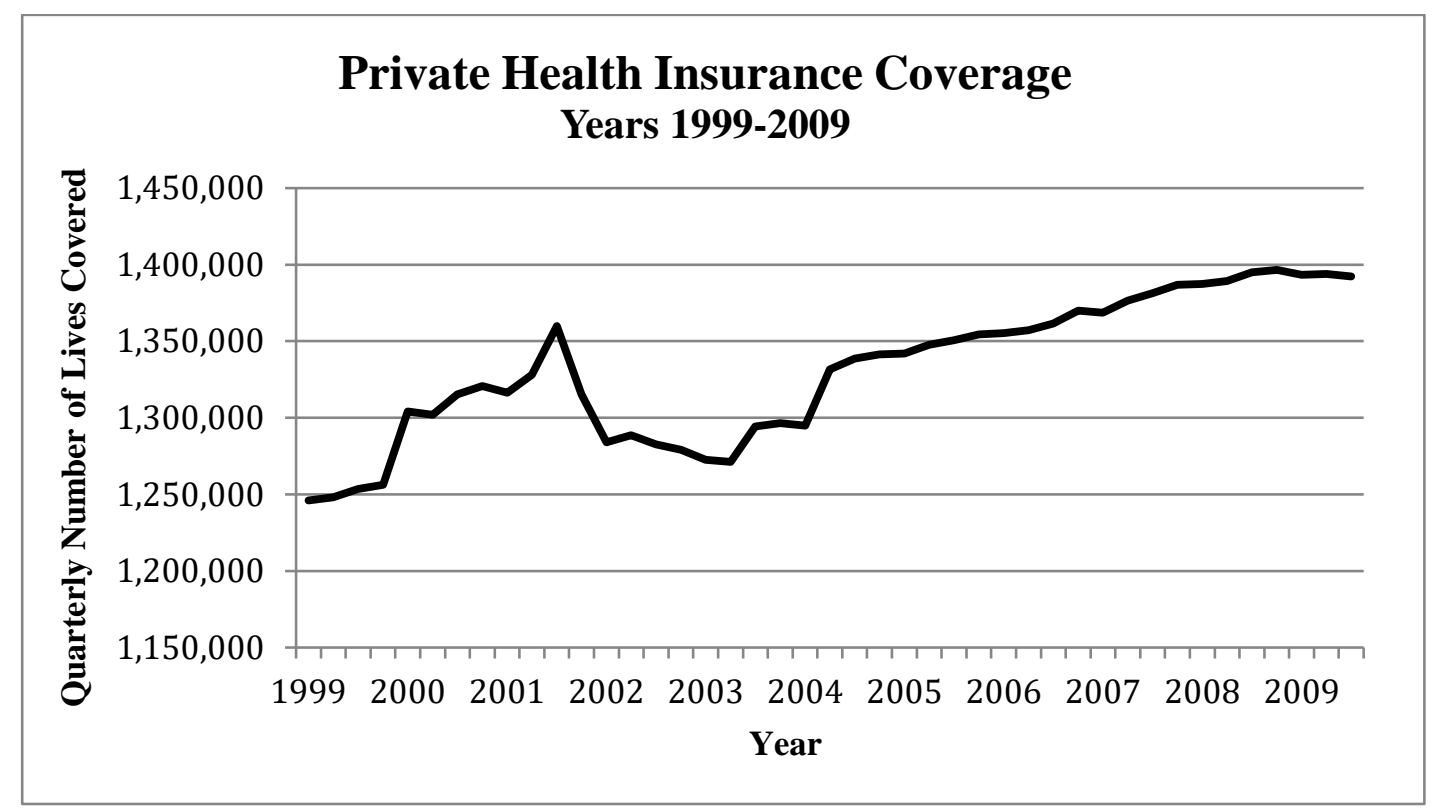


Figure 3.

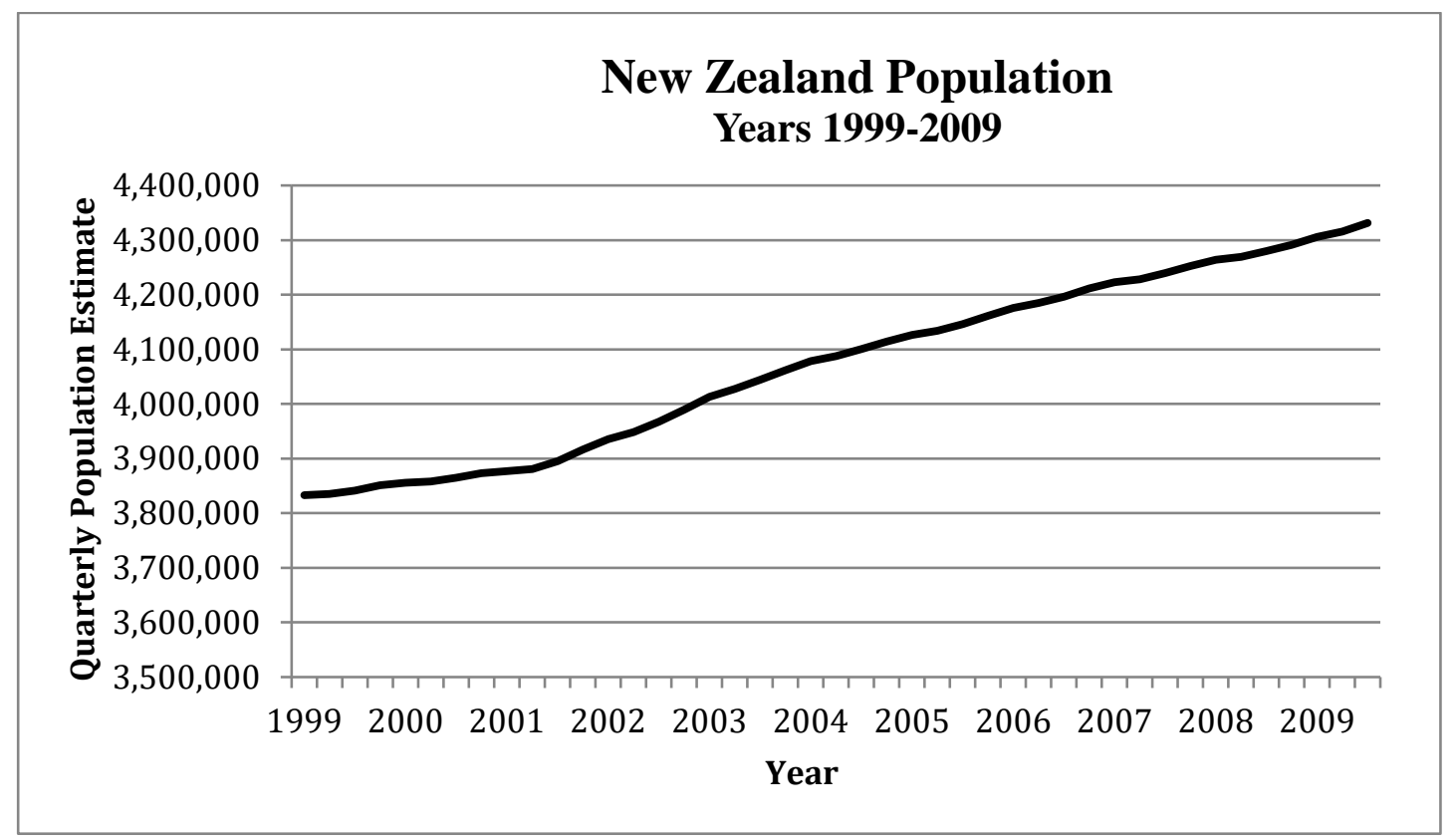


Figure 4.

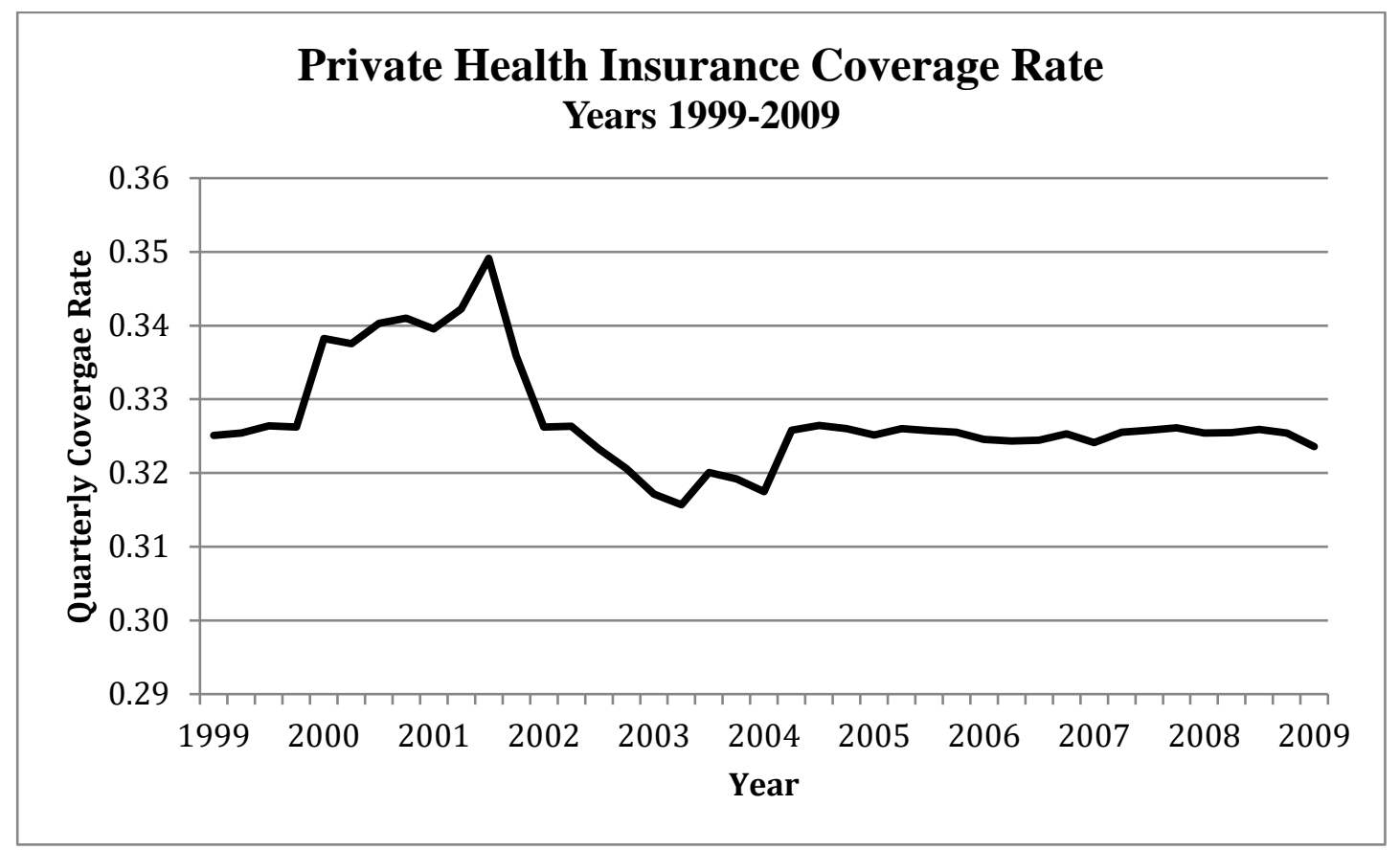


Table 1. Hypothesized Effects of an Increase in the Unemployment Rate on Private Health Insurance Coverage

\begin{tabular}{l|c|l}
\hline \multicolumn{1}{c|}{ Type of Effect } & $\begin{array}{c}\text { Impact on Private Health Insurance } \\
\text { Coverage }\end{array}$ & \multicolumn{1}{c}{$\begin{array}{c}\text { Particularly Affected } \\
\text { Groups }\end{array}$} \\
\hline \hline Income effect & $\downarrow$ & Elderly \\
\hline Employment effect & $\downarrow$ & Working-age men \\
\hline Certainty effect & $\uparrow$ & \\
\hline Pre-existing conditions & $\downarrow$ new contracts $>\downarrow$ existing contract & Elderly \\
\hline Health effect & $\downarrow / \uparrow /-$ & \\
\hline Overall effect & $\downarrow$ & Working-age men, elderly \\
\hline
\end{tabular}


Table 2. Private Health Insurance Coverage in New Zealand January 1999 - September 2009

\begin{tabular}{l|c|c}
\hline \hline & $\begin{array}{c}\text { Mean Number of } \\
\text { Lives Covered }\end{array}$ & $\begin{array}{c}\text { Mean Coverage } \\
\text { Rate }\end{array}$ \\
\hline Total Population & $1,331,210$ & 0.327 \\
\hline Male Population & 651,973 & 0.327 \\
\hline Female Population & 679,237 & 0.328 \\
\hline Elderly Population & 119,113 & 0.245 \\
\hline $\begin{array}{l}\text { Total Population: } \\
\text { New Lives Covered }\end{array}$ & 36,494 & 0.009 \\
\hline $\begin{array}{l}\text { Total Population: } \\
\text { Terminated Contracts }\end{array}$ & 33,654 & 0.008 \\
\hline
\end{tabular}


Table 3. The Effects of Unemployment Changes on Private Health Insurance Coverage, January 1999 - September 2009

\begin{tabular}{|c|c|c|}
\hline & $\begin{array}{c}\text { Total Number of Lives } \\
\text { Covered }\end{array}$ & Total Coverage Rate \\
\hline Unemployment Rate & $\begin{array}{c}-9,843 \\
(6,199) \\
\end{array}$ & $\begin{array}{c}-0.0032 * * \\
(0.0015) \\
\end{array}$ \\
\hline Total NZ Population & $\begin{array}{l}-0.2 \\
(0.4)\end{array}$ & - \\
\hline Year 2000 & $\begin{array}{c}55,156 * * * \\
(12,834) \\
\end{array}$ & $\begin{array}{c}0.0107 * * * \\
(0.0021)\end{array}$ \\
\hline Year 2001 & $\begin{array}{c}73,268 * * * \\
(24,309) \\
\end{array}$ & $\begin{array}{c}0.0109 * * * \\
(0.0029)\end{array}$ \\
\hline Year 2002 & $\begin{array}{c}38,387 \\
(47,418) \\
\end{array}$ & $\begin{array}{c}-0.0071 * * \\
(0.0031) \\
\end{array}$ \\
\hline Year 2003 & $\begin{array}{c}48,004 \\
(75,296)\end{array}$ & $\begin{array}{c}-0.0149 * * * \\
(0.0038)\end{array}$ \\
\hline Year 2004 & $\begin{array}{c}94,910 \\
(97,761)\end{array}$ & $\begin{array}{c}-0.0113 * * \\
(0.0048)\end{array}$ \\
\hline Year 2005 & $\begin{array}{c}123,667 \\
(114,569) \\
\end{array}$ & $\begin{array}{c}-0.0103^{*} \\
(0.0051) \\
\end{array}$ \\
\hline Year 2006 & $\begin{array}{c}146,037 \\
(132,001) \\
\end{array}$ & $\begin{array}{c}-0.0111 * * \\
(0.0051)\end{array}$ \\
\hline Year 2007 & $\begin{array}{c}169,962 \\
(147,762)\end{array}$ & $\begin{array}{l}-0.0109^{*} \\
(0.0053) \\
\end{array}$ \\
\hline Year 2008 & $\begin{array}{c}196,158 \\
(160,519) \\
\end{array}$ & $\begin{array}{c}-0.0092^{*} \\
(0.0046) \\
\end{array}$ \\
\hline Year 2009 & $\begin{array}{c}224,239 \\
(173,519)\end{array}$ & $\begin{array}{c}-0.0070 * * \\
(0.0026)\end{array}$ \\
\hline Quarter 2 & $\begin{array}{c}2,778 \\
(6,024) \\
\end{array}$ & $\begin{array}{l}-0.0006 \\
(0.0013)\end{array}$ \\
\hline Quarter 3 & $\begin{array}{l}12,886 \\
(9,603) \\
\end{array}$ & $\begin{array}{c}0.0003 \\
(0.0013)\end{array}$ \\
\hline Quarter 4 & $\begin{array}{c}13,101 \\
(14,789)\end{array}$ & $\begin{array}{l}-0.0017 \\
(0.0015)\end{array}$ \\
\hline Constant & $\begin{array}{c}2,045,727 \\
(1,336,773) \\
\end{array}$ & $\begin{array}{c}0.3484 * * * \\
(0.0114) \\
\end{array}$ \\
\hline R-squared & 0.97 & 0.93 \\
\hline
\end{tabular}

** and * indicate statistical significance at the $95 \%$ and the $90 \%$ confidence levels, respectively. Standard errors are reported in parentheses. 
Table 4. The Effects of Unemployment Changes on Private Health Insurance Coverage, Subsample Analysis, January 1999 - September 2009

\begin{tabular}{|c|c|c|c|c|}
\hline & $\begin{array}{c}\text { Number of Lives } \\
\text { Covered }\end{array}$ & $\begin{array}{l}\text { Implied \% } \\
\text { Change }\end{array}$ & Coverage Rate & $\begin{array}{c}\text { Implied \% } \\
\text { Change }\end{array}$ \\
\hline Total Population & $\begin{array}{l}\text { U: }-9,843 \\
\quad(6,199)\end{array}$ & $-0.74 \%$ & $\begin{array}{c}\mathrm{U}:-0.0032 * * \\
(0.0015)\end{array}$ & $-0.96 \%$ \\
\hline Male Population & $\begin{array}{l}\mathrm{U}:-4,660 \\
\quad(3,050)\end{array}$ & $-0.71 \%$ & $\begin{array}{c}\mathrm{U}:-0.0035^{* *} \\
(0.0015)\end{array}$ & $-1.07 \%$ \\
\hline Female Population & 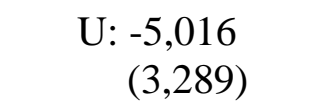 & $-0.74 \%$ & $\begin{array}{c}\mathrm{U}:-0.0028 * \\
(0.0016)\end{array}$ & $-0.86 \%$ \\
\hline Elderly Population & $\begin{array}{r}\mathrm{U}:-2,750^{*} \\
(1,609)\end{array}$ & $-2.31 \%$ & $\begin{array}{r}\mathrm{U}:-0.0004 \\
(0.0038)\end{array}$ & $-0.14 \%$ \\
\hline $\begin{array}{l}\text { Total Population: } \\
\text { New Lives Covered }\end{array}$ & $\begin{array}{l}\mathrm{U}: \begin{array}{l}-3,841 \\
(3,282)\end{array}\end{array}$ & $-10.52 \%$ & $\begin{array}{c}\mathrm{U}:-0.0014^{*} \\
(0.0008)\end{array}$ & $-15.57 \%$ \\
\hline $\begin{array}{l}\text { Total Population: } \\
\text { Terminated Contracts }\end{array}$ & $\begin{array}{l}\mathrm{U}: 1,211 \\
\quad(1,858)\end{array}$ & $3.60 \%$ & $\begin{array}{l}\text { U: } 0.0002 \\
(0.0004)\end{array}$ & $2.85 \%$ \\
\hline $\begin{array}{l}\text { Total Population: } \\
\text { Employment Rate on } \\
\text { RHS }\end{array}$ & $\begin{aligned} E: & 4,179 \\
& (6,167)\end{aligned}$ & $3.10 \%$ & $\begin{array}{r}\text { E: } 0.0019 \\
(0.0015)\end{array}$ & $0.57 \%$ \\
\hline $\begin{array}{l}\text { Total Population: } \\
\text { Current and Lagged } \\
\text { Unemployment Rate } \\
\text { on RHS }\end{array}$ & 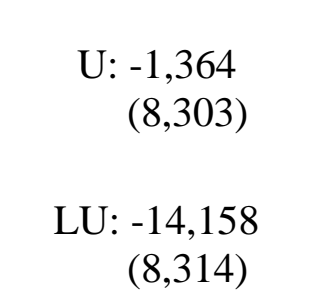 & $-1.17 \%$ & $\begin{array}{r}\mathrm{U}:-0.0014 \\
\quad(0.0022) \\
\text { LU: }-0.0030 \\
(0.0022)\end{array}$ & $-1.35 \%$ \\
\hline
\end{tabular}

' $U$ ' stands for the unemployment rate and ' $E$ ' for the employment rate. 'LU' is the one-period lag of the unemployment rate. $* *$ and $*$ indicate statistical significance at the $95 \%$ and the $90 \%$ confidence levels, respectively. Standard errors are reported in parentheses. 